Mathematics Instruction for Students With Disabilities: Applied Examples Using Virtual Manipulatives

Mikyung Shin ${ }^{1}$, Michelle Simmons ${ }^{1}$, Audrey Meador ${ }^{1}$, Francis J. Goode ${ }^{1}$, Alexa Deal ${ }^{1}$, and Tammye Jackson $^{1}$

${ }^{1}$ West Texas A\&M University

\begin{abstract}
Author Note
Mikyung Shin (D) https://orcid.org/0000-0001-7907-9193

Michelle Simmons (iD https://orcid.org/0000-0002-0391-2318

Audrey Meador (D) https://orcid.org/0000-0002-25108478
\end{abstract}




\begin{abstract}
Technology has changed the practices related to teaching and learning mathematics in schools. The demand for learning mathematics in virtual environments is imminent and increasing in the 21 st century classroom. There has been widespread expansion of the use of technology in education. The following article reviews three types of instruction-synchronous, asynchronous, and blended instruction — and provides applied examples regarding the use of virtual manipulatives in teaching mathematics to students with disabilities in the virtual environment. Keywords: asynchronous instruction, blended instruction, mathematics, synchronous instruction, virtual manipulatives
\end{abstract}




\section{Mathematics Instruction for Students With Disabilities: Applied Examples Using}

\section{Virtual Manipulatives}

With the combination of advanced technology and the development of software applications and virtual tools, mathematics teaching and learning have become interactive, engaging activities. One of the tools utilizing the advancement of technology for teaching mathematics is virtual manipulatives. Virtual manipulatives are defined as "an interactive, technology-enabled visual representation of a dynamic mathematical object" (Moyer-Packenham \& Bolyard, 2016, p. 13). Virtual manipulatives can be included in various technology environments, such as single-representation (interactive image only), multiple-representation (interactive visual models accompanied with numerical or text information), tutorials, gaming, and simulation (Moyer-Packenham \& Bolyard, 2016), encouraging students to engage in learning. Studies have revealed that students with disabilities who received mathematics interventions using virtual manipulatives showed both immediate effects and growth over time in various concepts and subjects within mathematics (Bouck et al., 2021; Park, Bryant, et al., 2021; Shin et al., 2021).

\section{Mathematics Instruction in the Virtual Environment}

As a global phenomenon, technology has changed the practices related to teaching and learning mathematics in schools. Specifically, technology helps teachers focus on mathematical problem solving and directly assists students by providing them with opportunities to engage in mathematics learning (Young, 2017). As educators gain experience from teaching online, they are actively planning and tailoring their lessons for virtual environments. Responding to the global needs of tailoring mathematics instruction in the virtual environment for all students, 
including those with disabilities, teachers can implement synchronous, asynchronous, and blended instruction.

\section{Synchronous Instruction}

Synchronous instruction represents real-time face-to-face online teaching using webbased learning tools (Hjalmarson, 2017; Yang et al., 2019). Versatile and advanced synchronous tools include video conferencing systems, electronic whiteboards, and interactive response systems, such as chat or instant messaging (Chappell et al., 2015; Yang et al., 2019). Synchronous online instruction is a research-supported teaching format for students with disabilities, increasing students' learning engagement (Coy et al., 2014). As an effective platform for virtual instructional delivery, the literature supports the use of synchronous virtual classrooms to assist with mathematical learning for low-performing third graders (Tsuei, 2017) and middle school students with mathematics difficulties in high-needs settings (Chappell et al., 2015). Meeting the guidelines of Universal Design for Learning (UDL; CAST, 2018), teachers can offer options of clarifying mathematics vocabulary and promoting student response through interactive discussions and poll questions.

\section{Asynchronous Instruction}

Asynchronous instruction comprises on-demand online instructional resources (e.g., prerecorded videos, downloadable course materials, online discussion boards, and self-paced online programs) made available for independent student access at a student's preferred time (Branon \& Essex, 2001; Magoulès \& Venet, 2018). Teachers can design and provide individualized instruction, thereby meeting students' learning goals and needs while considering their preference and availability (CAST, 2018). Varied formats of asynchronous mathematics learning have been identified as useful for students with disabilities in virtual mathematics classes (Rice, 
2018). For example, computer-assisted instruction has been widely provided for students with disabilities and has shown improved student outcomes in a wide range of mathematics domains, including word problems, fractions, number combinations, and whole-number computations (Kiru et al., 2018; Ok et al., 2020). As an extension of computer-assisted instruction, an intelligent tutoring system was developed and used within several online mathematics programs (Phillips et al., 2020). Furthermore, video modeling was found effective in teaching mathematics concepts and skills (e.g., fractions, geometry, and whole-number computation) to students with disabilities (Wright et al., 2020). The integration of video tutorials within a learning management system (e.g., Khan Academy) allows learners to personalize their learning experiences within the adapted learning environment (Vidergor \& Ben-Amram, 2020).

\section{Blended Instruction}

Blended instruction is traditionally considered an approach that integrates online and face-to-face classroom activities (Watson, 2008). In a blended, flipped learning environment, students learn new mathematical concepts and skills through pre-class video content at home, and then present their knowledge of mathematical problem-solving in class (Muir, 2020). Two alternative approaches allow live virtual learning for students who cannot participate in in-class activities: bichronous online learning and blended synchronous instruction. First, the bichronous online learning integrates asynchronous and synchronous instructions (Martin et al., 2020). Teachers can use a cloud-hosted learning management system (e.g., Blackboard) and integrate a live video conferencing with asynchronous lessons. Next, blended synchronous instruction is similar to teaching in multiple classrooms in different places, where teachers teach in a local classroom to students sitting in remote settings (i.e., home, different school campuses) simultaneously (Yang et al., 2019). Teachers provide instruction in a school-based classroom 
setting while students participate locally and remotely. Blended synchronous instruction is especially beneficial in increasing rural schools' access to highly qualified teachers by providing instructional delivery in a virtual format (Chappell et al., 2015; Yang et al., 2019).

\section{Use of Virtual Manipulatives}

Mathematics instruction using virtual manipulatives can be implemented in three ways: a) teacher-led instruction, b) teacher-guided instruction, and c) technology-assisted instruction (Bouck et al., 2021; Park, Bryant, et al., 2021; Shin et al., 2021). These instructional methods are effective for teaching mathematics to a wide-range of grade levels.

\section{Teacher-Led Instruction}

Within the research on virtual manipulatives, educators used teacher-led instruction, a high-leverage practice of explicit, systematic instruction (McLeskey et al., 2017). Interventionists provided explicit demonstrations for solving mathematical tasks using virtual manipulatives with a combination of think-aloud techniques to explain each mathematics problem-solving strategy, providing guided practice with feedback, and independent practice without any help or guidance from the instructor (Park, Bouck, et al., 2021). Regarding problem solving in multiplicative comparison, the effect of using virtual manipulatives was maintained even after visual supports (e.g., graphic organizer) were removed (Root et al., 2020).

\section{Teacher-Guided Instruction}

Within teacher-guided instruction, educators can use virtual manipulatives for students during the independent practice of newly acquired mathematical concepts and skills, or as an instructional booster to promote the maintenance of students' mathematical concepts (Bassette et al., 2020; Satsangi et al., 2018). This independent mathematical problem-solving can occur through individualized accommodations, in which teachers make virtual manipulatives 
accessible to everyone, including students who will benefit the most. As an avenue for differentiated instruction, teachers can use virtual manipulatives to allow certain students to work on solving problems independently and to provide more individualized guidance for those who need intensive support. As a caveat to use and to make connections between the virtual models and the mathematics they represent, teachers can provide students with opportunities to practice communicating their mathematical thinking to peers and teachers.

\section{Technology-Assisted Instruction}

Technology-assisted instruction (commonly referred to as computer-assisted instruction) is an instructional method in which software programs support students' mathematical learning as a primary interventionist or a tutor. Technology-assisted instruction, including virtual manipulatives, is embedded in various types of technology, such as games, tablet apps, and websites. Furthermore, design features embedded in technology-assisted instruction for students with disabilities include various other instructional strategies, such as explicit instruction (cumulative review, lesson goals, explicit modeling, guided practice, and independent practice), strategy instruction (cognitive problem-solving steps and metacognitive self-monitoring strategies), and multiple media and materials (Ok et al., 2020). Many virtual manipulative websites and programs are accompanied by auditory prompts or embedded directions that inherently guide learning (Shin et al., 2017). These technological platforms may also provide feedback to inform students when their attempts to solve the problem are correct or incorrect.

\section{Applied Examples: Using Virtual Manipulatives in the Virtual Environment}

To illustrate implementation of virtual manipulatives in the virtual environment, the following vignettes are drawn from fictionalized accounts or authentic situations (see Note). 
Mr. Phillips is a special education mathematics teacher at Horizons Middle School. Teachers, including Mr. Phillips, have been implementing virtual instruction for students who attend schools remotely. Mr. Phillips analyzed the most recent progress-monitoring benchmark assessment data for one of his sixth-grade students with learning disabilities, Analisa. Despite his targeted instruction on how to use word problems involving multiplication with fractions, Analisa's performance at the end-of-year benchmark assessment was below average compared to her classmates, earning a score in the 10th percentile. It is apparent that Analisa struggles with learning fraction word problem-solving and is challenged by the newest approach to instructional delivery, virtual learning.

\section{Applied Example 1: Teacher-Led Instruction}

Teacher-led instruction can be used within synchronous instruction as well as blended instruction. In the virtual learning environment (e.g., Google Meet, Zoom), teachers can promptly demonstrate how to solve problems and deliver scaffolds through the shared whiteboard. Mr. Phillips sometimes creates his own virtual manipulatives using built-in functions within the software, interactive whiteboards, and smart apps. Table 1 shows a list of the free authoring tools that can be used to create virtual manipulatives using interactive whiteboards (e.g., Nearpod, Google Jamboard, and OpenBoard) or built-in functions of app- and web-based virtual manipulatives (e.g., Didax and Math Learning Center). Through the online sample lessons and video tutorials shared through the publishers' websites (e.g., https://classkick.com), teachers can receive training on creating lesson content. Encouraging students' motivation in learning mathematics, Mr. Phillips incorporates students' favorite items into word problems involving fractions and uses image files to create class virtual manipulatives. 
The following procedures show how to create virtual manipulatives using editing tools on the interactive whiteboard:

- Prepare an image file (e.g., .jpg or .png) and upload it to the interactive whiteboard.

- Edit (create multiple images aligned with mathematical problem situations) the image files and locate them on the whiteboard.

- Share the interactive whiteboard.

- Send a shared link or display a QR code to students so they can manipulate the virtual manipulatives and solve the problems.

- Save students' work by downloading the file or taking a screenshot of students' final solutions.

\section{[INSERT TABLE 1 HERE]}

When Mr. Phillips employs blended synchronous instruction, he displays the virtual manipulatives to the whole class via projection. Meanwhile, Analisa, who participates remotely, directly responds through the classroom desktop screen. Using interactive whiteboards, Mr. Phillips calls on individual students in either the local or virtual classroom to manipulate the virtual objects for the whole class. Students engage in exploring virtual manipulatives through the shared screen via video conferencing remotely or the local classroom's smart boards. Applying technological devices that exist in the classroom, such as computers or tablets, Mr. Phillips projects virtual manipulative handling while simultaneously directing students to perform the same procedure on their individual consoles using their own devices. By enabling simultaneous screen-sharing with all students, Mr. Phillips can view each student's progress (e.g., gallery-view in Zoom, screen sharing in Nearpod). He can also select one notable work among students' shared screens to view with the whole class. 


\section{Applied Example 2: Teacher-Guided Instruction}

Teacher-guided instruction can also be used within synchronous or blended instruction. Teachers can provide ongoing progress monitoring of students' mathematical learning and promote multiple opportunities for students to verbally express and visualize targeted mathematical concepts. Mr. Phillips sets students to work in small groups on a task utilizing virtual manipulatives. He then requires a presentation of their ability to determine a solution with the virtual manipulative tool. Instruction in this way allows Mr. Phillips to facilitate students' independent mathematical problem solving. With the implementation of a systematic prompt, such as a system of the least prompts (starting from the last gesture to the use of indirect or direct verbal and teacher-directed modeling), students are encouraged to develop independent problemsolving abilities. Promoting the conceptual understanding of mathematical problem solving using virtual manipulatives, Mr. Phillips presents a "why" question, asking, "Why did you partition the fraction bar?" Students can respond to the teacher through an interactive quiz and actively engage in the process of checking for understanding. Table 2 displays a list of the video conferencing platforms and video content management systems that Mr. Phillips can use in the virtual environment.

\section{[INSERT TABLE 2 HERE]}

\section{Applied Example 3: Technology-Assisted Instruction}

Technology-assisted instruction can be used within asynchronous instruction. Mr. Phillips uses a web-based interactive computer application, Fun Fraction (http://funfraction.org), to supplement lessons for Analisa on solving word problems involving multiplying fractions. At each session, Analisa watches a five-minute video demonstrating how to solve each fraction word problem for seven lessons. Analisa then solves two guided practices and five independent 
practices, while checking her progress on the screen. For example, in Lesson 1, when solving the word problem of, "One tray holds $\frac{2}{3}$ of the pie. How much pie would there be on 4 trays?" Analisa employs the following problem-solving steps: Read (read the problem), Restate (click and highlight all important information), Represent (represent the problem using an area model), and Answer (write the equation and answer it). Extending her previous understanding of multiplication to fractions, she identifies the multiplicand $\left(\frac{2}{3}\right.$ of the pie in one tray $=$ number of units in one group) and the multiplier (4 trays of pie = number of equal groups), representing these in the built-in area model of Fun Fraction. Then, the product is determined by examining the number of pies in four trays with the following equation: " $4 \times \frac{2}{3}=\frac{8}{3}=2 \frac{2}{3}$ pie." Analisa monitors her own problem-solving action in each step, responding to the self-regulatory message embedded in the website (e.g., "Did I represent the problem correctly?" in Represent). Table 3 offers a list of learning management systems that provide authoring tools to develop lesson content for asynchronous online instruction.

\section{[INSERT TABLE 3 HERE]}

\section{Concluding Thoughts}

Innovations in computer technology shift the manipulation of objects in the physical mathematics classroom to the manipulation of those same objects on a computer screen, or a virtual mathematics classroom. As the use of technology in schools has greatly increased, so has the use of virtual manipulatives for mathematics instruction. While teaching mathematical problem solving to students with disabilities, teachers such as Mr. Phillips can consider several benefits and challenges of using virtual manipulatives in the virtual environment.

Indeed, numerous benefits for mathematics instruction exist with the incorporation of virtual manipulatives in the digital mathematics classroom. The suggested features for using 
virtual manipulatives as a viable asset to mathematics instruction can be argued as follows (Bouck \& Sprick, 2019; Satsangi et al., 2018; Shin et al., 2017): Virtual manipulatives can be utilized by students for which the under-development of fine motor skills make working with concrete manipulatives challenging, provide an avenue to differentiate virtual instruction by offering the ability to turn off or hide certain features to support multiple levels of learners, have an endless supply of virtual manipulatives with the ability to quickly work with more than one model, easily display student strategies and work with the virtual manipulatives using screensharing features, reduce the need to search for or build concrete manipulatives for mathematics concepts that are difficult to model, and provide numerous opportunities for practice with multiple virtual manipulatives.

While the benefits of instruction using virtual manipulatives show promise, there are considerations that must be noted when these tools are used in the virtual environment. Although virtual manipulatives can be utilized in place of concrete manipulatives, students and teachers must undergo proper training in their use and know how to integrate them into their teaching; teachers and students are also encouraged to watch video tutorials provided by virtual manipulatives applications and websites (Shin et al., 2017). Virtual manipulatives do offer costand space-saving measures as opposed to purchasing several concrete manipulatives for use in the classroom; however, not all virtual manipulatives are without charge. Moreover, deliberation regarding the use of virtual manipulatives in the virtual classroom setting must also consider compatibility with operating systems (Microsoft, MacIntosh, Google, etc.) and devices (mobile versus desktop). Depending on the technology and its use, students can show various reasonings, strategies, and readiness with mathematical concepts through participation in the technology-rich mathematics environment. Considering students' and families' preferences and accessibility, 
teachers can plan multiple ways of participating in virtual classrooms by using virtual manipulatives. As a final thought, teachers and researchers need to consider and investigate student diversity in order to maximize equity in learning mathematics in the virtual environment. Note

The vignettes regarding applied examples 1 and 2 were fictionalized accounts drawn from the research literature and not based on actual people or events that were observed by the authors. The vignette regarding the applied example 3 was based on an authentic situation observed by the authors; the name is a pseudonym to protect the privacy of the subject. 


\section{References}

Bassette, L., Bouck, E., Shurr, J., Park, J., Cremeans, M., Rork, E., Miller, K., \& Geiser, S. (2020). A comparison of manipulative use on mathematics efficiency in elementary students with autism spectrum disorder. Journal of Special Education Technology, 35(4), 179-190. https://doi.org/10.1177/0162643419854504

Bouck, E. C., Anderson, R. D., Long, H., \& Sprick, J. (2021). Manipulative-based instructional sequences in mathematics for students with disabilities. TEACHING Exceptional Children. Advance online publication. https://doi.org/10.1177/0040059921994599

Bouck, E. C., \& Sprick, J. (2019). The virtual-representational-abstract framework to support students with disabilities in mathematics. Intervention in School and Clinic, 54(3), 173180. https://doi.org/10.1177/1053451218767911

Branon, R. F., \& Essex, C. (2001). Synchronous and asynchronous communication tools in distance education. TechTrends, 45(1), 36-42.

CAST. (2018). Universal Design for Learning guidelines version 2.2. http://udlguidelines.cast.org

Chappell, S., Arnold, P., Nunnery, J., \& Grant, M. (2015). An examination of an online tutoring program's impact on low-achieving middle school students' mathematics achievement. Online Learning, 19(5), 37-53.

Coy, K., Marino, M. T., \& Serianni, B. (2014). Using universal design for learning in synchronous online instruction. Journal of Special Education Technology, 29(1), 63-74. https://doi.org/10.1177/016264341402900105 
Hjalmarson, M. A. (2017). Learning to teach mathematics specialists in a synchronous online course: a self-study. Journal of Mathematics Teacher Education, 20(3), 281-301. https://doi.org/10.1007/s10857-015-9323-x

Kiru, E. W., Doabler, C. T., Sorrells, A. M., \& Cooc, N. A. (2018). A synthesis of technologymediated mathematics interventions for students with or at risk for mathematics learning disabilities. Journal of Special Education Technology, 33(2), 111-

123. https://doi.org/10.1177/0162643417745835

Magoulès, F., \& Venet, C. (2018). Asynchronous iterative sub-structuring methods. Mathematics and Computers in Simulation, 145, 34-49. https://doi.org/10.1016/j.matcom.2016.05.009

Martin, F., Polly, D., \& Ritzhaupt, A. (2020). Bichronous online learning: Blending asynchronous and synchronous online learning. EDUCAUSE Review. https://er.educause.edu/articles/2020/9/bichronous-online-learning-blendingasynchronous-and-synchronous-online-learning

McLeskey, J., Barringer, M-D., Billingsley, B., Brownell, M., Jackson, D., Kennedy, M., Lewis, T., Maheady, L., Rodriguez, J., Scheeler, M. C., Winn, J., \& Ziegler, D. (2017). Highleverage practices in special education. Council for Exceptional Children \& CEEDAR Center.

Moyer-Packenham, P. S., \& Bolyard, J. J. (2016). Revisiting the definition of a virtual manipulative. In P. S. Moyer-Packenham (Ed.), International perspectives on teaching and learning mathematics with virtual manipulatives (pp. 3-23). Springer.

Muir, T. (2020). Self-determination theory and the flipped classroom: a case study of a senior secondary mathematics class. Mathematics Education Research Journal. Advance online publication. https://doi.org/10.1007/s13394-020-00320-3 
Ok, M. W., Bryant, D. P., \& Bryant, B. R. (2020). Effects of computer-assisted instruction on the mathematics performance of students with learning disabilities: A synthesis of the research. Exceptionality, 28(1), 30-44. https://doi.org/10.1080/09362835.2019.1579723

Park, J., Bouck, E. C., \& Fisher, M. H. (2021). Using the virtual-representational-abstract with overlearning instructional sequence to students with disabilities in mathematics. The Journal of Special Education, 54(4), 228-238. https://doi.org/10.1177/0022466920912527

Park, J., Bryant, D. P., \& Shin, M. (2021). Effects of interventions using virtual manipulatives for students with learning disabilities: A synthesis of single-case research. Journal of Learning Disabilities. Advance online publication. https://doi.org/10.1177/00222194211006336

Phillips, A., Pane, J. F., Reumann-Moore, R., \& Shenbanjo, O. (2020). Implementing an adaptive intelligent tutoring system as an instructional supplement. Educational Technology Research and Development, 68, 1-29. https://doi.org/10.1007/s11423-020-09745-w

Rice, M. F. (2018). Supporting literacy with accessibility: Virtual school course designers' planning for students with disabilities. Online Learning, 22(4), 161-179. https://files.eric.ed.gov/fulltext/EJ1202365.pdf

Root, J. R., Cox, S. K., Gilley, D., \& Wade, T. (2020). Using a virtual-representational-abstract integrated framework to teach multiplicative problem solving to middle school students with developmental disabilities. Journal of Autism and Developmental Disorders. Advance online publication. https://doi.org/10.1007/s10803-020-04674-2

Satsangi, R., Hammer, R., \& Hogan, C. D. (2018). Studying virtual manipulatives paired with explicit instruction to teach algebraic equations to students with learning disabilities. 
Learning Disability Quarterly, 41(4), 227-242. https://doi.org/10.1177/0731948718769248

Shin, M., Bryant, D. P., Bryant, B. R., McKenna, J. W., Hou, F., \& Ok, M. W. (2017). Virtual manipulatives: Tools for teaching mathematics to students with learning disabilities. Intervention in School and Clinic, 52(3), 148-153. https://doi.org/10.1177/1053451216644830

Shin, M., Park, J., Grimes, R., \& Bryant, D. P. (2021). Effects of using virtual manipulatives for students with disabilities: Three-level multilevel modeling for single-case data. Exceptional Children. Advance online publication. https://doi.org/10.1177/00144029211007150

Tsuei, M. (2017). Learning behaviours of low-achieving children's mathematics learning in using of helping tools in a synchronous peer-tutoring system. Interactive Learning Environments, 25(2), 147-161. https://doi.org/10.1080/10494820.2016.1276078

Vidergor, H. E., \& Ben-Amram, P. (2020). Khan academy effectiveness: The case of math secondary students’ perceptions. Computers \& Education, 157, Article 103985. https://doi.org/10.1016/j.compedu.2020.103985

Watson, J. (2008). Blended learning: The convergence of online and face-to-face education. Promising practices in online Learning. North American Council for Online Learning. https://files.eric.ed.gov/fulltext/ED509636.pdf

Wright, J. C., Knight, V. F., \& Barton, E. E. (2020). A review of video modeling to teach STEM to students with autism and intellectual disability. Research in Autism Spectrum Disorders, 70, Article 101476. https://doi.org/10.1016/j.rasd.2019.101476 
Yang, J., Yu, H., \& Chen, N. S. (2019). Using blended synchronous classroom approach to promote learning performance in rural area. Computers \& Education, 141, Article 103619. https://doi.org/10.1016/j.compedu.2019.103619

Young, J. (2017). Technology-enhanced mathematics instruction: A second-order meta-analysis of 30 years of research. Educational Research Review, 22, 19-33.

https://doi.org/10.1016/j.edurev.2017.07.001 
Table 1

Free Authoring Tools to Create Virtual Manipulatives

\begin{tabular}{|c|c|c|}
\hline Name & Website & Compatibility \\
\hline \multicolumn{3}{|c|}{ Create virtual manipulatives using interactive whiteboards } \\
\hline Classkick & https://classkick.com & $\mathrm{W}, \mathrm{M}, \mathrm{iOS}, \mathrm{An}, \mathrm{Ch}$ \\
\hline Google Jamboard & https://jamboard.google.com & $\mathrm{W}, \mathrm{M}, \mathrm{iOS}, \mathrm{An}, \mathrm{Ch}^{\mathrm{a}}$ \\
\hline Lucidspark & https://lucidspark.com & $\mathrm{W}, \mathrm{M}, \mathrm{iOS}, \mathrm{An}, \mathrm{Ch}^{\mathrm{a}}$ \\
\hline Nearpod & https://nearpod.com & $\mathrm{W}, \mathrm{M}, \mathrm{iOS}, \mathrm{An}, \mathrm{Ch}^{\mathrm{a}}$ \\
\hline OpenBoard & https://openboard.ch/index.en.html & $\mathrm{W}, \mathrm{M}, \mathrm{Ch}$ \\
\hline Whiteboard.fi & https://whiteboard.fi & $\mathrm{W}, \mathrm{M}, \mathrm{iOS}, \mathrm{An}, \mathrm{Ch}$ \\
\hline \multicolumn{3}{|c|}{ Create new problems using built-in functions } \\
\hline CPM Tiles & https://technology.cpm.org/general/tiles & $\mathrm{W}, \mathrm{M}, \mathrm{iOS}, \mathrm{An}, \mathrm{Ch}$ \\
\hline Desmos & https://www.desmos.com & $\mathrm{W}, \mathrm{M}, \mathrm{iOS}, \mathrm{An}, \mathrm{Ch}^{\mathrm{a}}$ \\
\hline Didax & $\begin{array}{l}\text { https://www.didax.com/math/virtual- } \\
\text { manipulatives.html }\end{array}$ & W, M, iOS, An, Ch \\
\hline Fun Fraction & http://funfraction.org & $\mathrm{W}, \mathrm{M}, \mathrm{iOS}, \mathrm{An}, \mathrm{Ch}$ \\
\hline GeoGebra & https://www.geogebra.org/m/NPDu3rCm & $\mathrm{W}, \mathrm{M}, \mathrm{iOS}, \mathrm{An}, \mathrm{Ch}^{\mathrm{a}}$ \\
\hline Illuminations & https://illuminations.nctm.org & $\mathrm{W}, \mathrm{M}, \mathrm{iOS}, \mathrm{An}, \mathrm{Ch}$ \\
\hline Math Learning Center & https://www.mathlearningcenter.org/apps & $\mathrm{W}, \mathrm{M}, \mathrm{iOS}, \mathrm{An}, \mathrm{Ch}^{\mathrm{a}}$ \\
\hline Math Playground & https://www.mathplayground.com & $\mathrm{W}, \mathrm{M}, \mathrm{iOS}, \mathrm{An}, \mathrm{Ch}$ \\
\hline $\begin{array}{l}\text { National Library of Virtual } \\
\text { Manipulatives }\end{array}$ & http://nlvm.usu.edu/en/nav/vlibrary.html & $\mathrm{W}, \mathrm{M}$ \\
\hline Toy Theater & $\begin{array}{l}\text { https://toytheater.com/category/teacher- } \\
\text { tools/virtual-manipulatives }\end{array}$ & W, M, iOS, An, Ch \\
\hline
\end{tabular}

Note. An = Android $; \mathrm{Ch}=$ Chrome; $\mathrm{M}=\mathrm{Mac} ; \mathrm{W}=$ Windows.

${ }^{a}$ Chrome extension is available. 
Table 2

Video Conferencing and Content Management Systems

\begin{tabular}{|c|c|c|}
\hline Feature & Website & Compatibility \\
\hline \multicolumn{3}{|c|}{ Video conferencing platforms } \\
\hline $\begin{array}{l}\text { Google Meet: Live video and streaming, } \\
\text { screen sharing and recording, live } \\
\text { captioning, screen reader and } \\
\text { magnifiers, and the co-creation of } \\
\text { documents }\end{array}$ & https://apps.google.com/meet & $\mathrm{W}, \mathrm{M}, \mathrm{iOS}, \mathrm{An}, \mathrm{Ch}^{\mathrm{a}}$ \\
\hline $\begin{array}{l}\text { Microsoft Teams: Live video and } \\
\text { streaming, screening sharing and } \\
\text { recording, pre-recorded video, live } \\
\text { captioning, screen reader, interactive } \\
\text { whiteboard, and blurring backgrounds }\end{array}$ & $\begin{array}{l}\text { https://www.microsoft.com/e } \\
\text { n-us/microsoft-teams/group- } \\
\text { chat-software }\end{array}$ & $\mathrm{W}, \mathrm{M}, \mathrm{iOS}, \mathrm{An}, \mathrm{Ch}^{\mathrm{a}}$ \\
\hline $\begin{array}{l}\text { WebEx: Live video and streaming, } \\
\text { screening sharing and recording, live } \\
\text { captioning, screen reader, interactive } \\
\text { whiteboard, and breakout sessions }\end{array}$ & https://www.webex.com & $\mathrm{W}, \mathrm{M}, \mathrm{iOS}, \mathrm{An}, \mathrm{Ch}^{\mathrm{a}}$ \\
\hline $\begin{array}{l}\text { Zoom: Live video and streaming, screen } \\
\text { sharing and recording, typed } \\
\text { captioning, screen reader, interactive } \\
\text { whiteboard, and breakout sessions }\end{array}$ & https://zoom.us & $\mathrm{W}, \mathrm{M}, \mathrm{iOS}, \mathrm{An}, \mathrm{Ch}^{\mathrm{a}}$ \\
\hline \multicolumn{3}{|c|}{ Video content management systems } \\
\hline $\begin{array}{l}\text { Panopto: Creation and sharing of on- } \\
\text { demand videos, live streaming, screen } \\
\text { sharing and recording, live captioning } \\
\text { and subtitles, and smart searches }\end{array}$ & https://www.panopto.com & $\mathrm{W}, \mathrm{M}, \mathrm{iOS}, \mathrm{An}, \mathrm{Ch}^{\mathrm{a}}$ \\
\hline $\begin{array}{l}\text { Vimeo: Creation and sharing of on- } \\
\text { demand videos, live streaming, screen } \\
\text { sharing and recording, live captioning } \\
\text { and subtitles, and video file transfer }\end{array}$ & https://vimeo.com & $\mathrm{W}, \mathrm{M}, \mathrm{iOS}, \mathrm{An}, \mathrm{Ch}^{\mathrm{a}}$ \\
\hline
\end{tabular}

Note . An = Android $; \mathrm{Ch}=$ Chrome; $\mathrm{M}=\mathrm{Mac} ; \mathrm{W}=$ Windows.

${ }^{a}$ Chrome extension is available. 
Table 3

Learning Management Systems (Authoring Tools to Develop Lesson Content)

Feature

Blackboard Learn: Grading assignments and tests, discussion boards, copying lessons, and attendance tracking

Canvas: Grading assignments and tests, collaborative workspace, recording or uploading of audio and video, and Google Classroom integration

Google Classroom: Creating assignments, automatic grading, organizational tools, and family communication

Moodle: Personalized dashboard, forums, wikis, database activities, all-in-one calendar, and multilingual capabilities

Seesaw: Admin dashboard visibility and connection, streamlining of assessments, customization and management of standards, family engagement, and family messaging

SoftChalk: Annotated text, tracking student outcomes, cloud collaboration, free learning materials, and multi-platform authoring https://www.instructure.com/ W, M, iOS, An, $\mathrm{Ch}^{\text {a }}$ canvas/k-12

https://edu.google.com

W, M, iOS, An, $\mathrm{Ch}^{\mathrm{a}}$

https://moodle.org

W, M, iOS, An, $\mathrm{Ch}^{\text {a }}$

https://web.seesaw.me

W, M, iOS, An, $\mathrm{Ch}^{\text {a }}$

https://softchalk.com W, M, iOS, An, Ch

Note. An = Android , $\mathrm{Ch}=$ Chrome; $\mathrm{M}=$ Mac; $\mathrm{W}=$ Windows.

${ }^{\text {a }}$ Chrome extension is available. 